\title{
Rethinking the Criminalization of Personal Substance Use and Possession
}

\author{
Robert A. Kleinman, $M D^{1,2}$ (1) and Nathaniel P. Morris, $M D^{3}$ \\ 'Massachusetts General Hospital, 55 Fruit St., Boston, MA, USA; ${ }^{2}$ Harvard Medical School, Boston, MA, USA; ${ }^{3}$ University of California San Francisco, \\ San Francisco, CA, USA.
}

$\mathrm{J}$ Gen Intern Med

DOI: $10.1007 / \mathrm{s} 11606-021-06628-5$

(c) Society of General Internal Medicine 2021

$\mathrm{I}_{\mathrm{a}}^{\mathrm{n}}$ n November 2020, a majority of voters in Oregon approved a ballot measure to decriminalize personal possession of controlled substances. Once implemented, this measure would reclassify these offenses as non-criminal violations and replace criminal penalties with a $\$ 100$ fine or the option of completing a health assessment at a designated treatment facility. The measure would also redirect cannabis-related tax revenues and criminal justice savings to fund addiction treatment services, among other programs. Oregon's ballot measure does not legalize commercial sale of all controlled substances for recreational use or expunge prior drug-related criminal records. Although some US cities and the District of Columbia have decriminalized personal substance use and possession (PSUP) of certain controlled substances beyond cannabis, such as psilocybin, Oregon is poised to become the first state to decriminalize PSUP of all controlled substances. While PSUP of controlled substances can incur federal criminal charges, enforcement of PSUP laws most often falls to state and local authorities. ${ }^{1}$ The passage of Oregon's ballot measure thus represents a profound departure from traditional US policies toward PSUP, and its implementation warrants careful study given the potential to influence substance-related policy elsewhere.

The use of psychoactive substances is common in the USA. For some people, PSUP may be non-problematic or recreational. For others, PSUP may be secondary to a substance use disorder (SUD), which can involve significant functional impairment, morbidity, and mortality. The 2019 National Survey on Drug Use and Health (NSDUH) estimated that 165.4 million people aged 12 or older used substances in the month prior, including 139.7 million who drank alcohol, 58.1 million who used tobacco, and 35.8 million who used illicit drugs.

Received November 15, 2020

Accepted January 14, 2021
Meanwhile, 20.4 million people aged 12 or older met criteria for a SUD, more than 70,000 died of drug-related overdoses.

Criminal justice systems across the country continue to put people in handcuffs, squad cars, police departments, courtrooms, jails, prisons, and probation and parole offices for PSUP. In 2019, there were more than 1.56 million arrests for drug-related offenses, of which $87 \%$ were for possession according to the Federal Bureau of Investigation (FBI). More than 249,000 people were under the jurisdiction of US federal and state correctional systems for drug-related offenses, including more than 46,000 people for possession, in 2018 . $^{1}$ Surveys indicate that approximately $60 \%$ of individuals incarcerated in jails and state prisons meet diagnostic criteria for drug abuse or dependence. ${ }^{2}$

The selective criminalization of PSUP in the USA has disproportionately affected racial minorities. For example, the Anti-Drug Abuse Act of 1986 established a 5-year mandatory minimum sentence for possession of 5 grams of crack cocaine; the same sentence required 500 grams of powder cocaine, which is typically more expensive and likely to be used by affluent and White individuals. ${ }^{3}$ A 2006 report estimated that more than $80 \%$ of defendants sentenced under federal crack cocaine laws were Black, even though more than $66 \%$ of crack cocaine users were White or Hispanic. ${ }^{3}$ These types of disparities occur with other drugs as well. A study in Seattle found that $64 \%$ of individuals arrested for drug delivery between January 1999 and April 2001 were Black, despite a majority of drug deliveries being by White individuals. ${ }^{4}$ From 1987 to 2014, there was over one arrest for drug possession per 100 Black adults each year; these annual rates of arrest were between 2.5 and 4.4 times greater than those for White adults, although evidence suggests Black and White adults use illicit substances at comparable rates. ${ }^{5}{ }^{6}$ Being arrested can be frightening, stigmatizing, and potentially lifethreatening. Moreover, an arrest may start a cascading sequence of legal involvement that can further perpetuate racial inequities: bail policies that determine who is detained pretrial, charging decisions by prosecutors, inadequate funding and shortages of public defenders, and sentencing disparities are among many aspects of the criminal justice system that may disproportionately affect minorities, as well as poor and other disadvantaged defendants, arrested for PSUP. Black and Hispanic individuals represent less than a third of the US population; still, among individuals under the jurisdiction of 
state correctional authorities during 2018 with a drug-related offense listed as their most serious offense, 80,900 (46\%) of 176,300 were Black or Hispanic. ${ }^{1}$ Criminal justice involvement for PSUP can extend far beyond arrest, adjudication, and incarceration, as people may face months or years of community-based supervision through probation or parole. Criminal records related to PSUP follow millions of people in the USA, limiting opportunities to drive, to find employment, or even to vote.

Some argue that criminalization of substance use can serve specific functions. For example, criminalization of PSUP might deter people from using substances. However, in an analysis of 2014 data across the country, the Pew Charitable Trusts found that rates of drug-related imprisonment were not associated with rates of drug use, overdose deaths, or arrests. ${ }^{7}$ Furthermore, despite widespread criminalization of PSUP, 57.2 million Americans aged 12 or older still reported using illicit drugs in the past year, and 8.3 million had a SUD related to illicit drugs, according to the 2019 NSDUH.

Rehabilitation may be another goal of criminalizing PSUP, with the aim of reducing subsequent PSUP and recidivism; however, traditional approaches to arrest and incarceration have a tenuous record in achieving these goals. Among more than 120,000 individuals released from incarceration for drugrelated offenses in 30 states between 2005 and 2014, 84\% were re-arrested for any offense and more than $60 \%$ were rearrested for drug offenses within 9 years. ${ }^{8}$ Treatment is often difficult to access for justice-involved individuals with SUDs, and many do not receive evidence-based care, placing them at risk for adverse health outcomes; in North Carolina, people released from incarceration had opioid overdose death rates 40 times greater than the general population in the 2 weeks after release. ${ }^{9}$ In a separate study of individuals released from New York state prisons, each year of time spent in prison was associated with a 2-year decrease in life expectancy. ${ }^{10}$

Criminalization can support state-sanctioned retribution against individuals who harm others. The potential harms of PSUP are often limited to the health of the user; still, PSUP can lead to intoxication, dependence, and behaviors that might harm others. In the landmark case Robinson v. California, a man contested a California statute after police officers noticed needle marks on his arm and arrested him for narcotic addiction. The US Supreme Court struck down the law, with the majority contending that criminalizing the status of having an illness violated constitutional protections against cruel and unusual punishment. By comparison, in a 1968 case Powell $v$. Texas, a man challenged his conviction for public drunkenness, making a similar argument that he was being criminalized for alcoholism. Yet the US Supreme Court disagreed, with a plurality finding that public conduct associated with alcoholism, rather than alcoholism itself, could serve as the basis for criminal charges. The ballot measure in Oregon does not decriminalize driving under the influence, theft, or other violent acts that may be associated with substance use.
Delivering the opinion in the 1962 Robinson decision, Justice Potter Stewart noted that governments can tackle illicit substance use through various policies, such as criminalization or compulsory treatment. However, he added that, "a State might choose to attack the evils of narcotics traffic on broader fronts also-through public health education, for example, or by efforts to ameliorate the economic and social conditions under which those evils might be thought to flourish." Nearly 60 years later, US policies that criminalize PSUP do not seem to effectively manage the health-related effects of substance use, yet contribute to mass arrest and incarceration, exacerbate racial and socioeconomic disparities, cost billions to taxpayers, and perpetuate stigmatization of substance use.

Alternatives exist to an arrest-and-incarcerate approach to PSUP. Many jurisdictions in the USA have adopted drug court models, which can require people arrested for PSUP to participate in drug screening, treatment, and court sessions instead of incarceration. Some evidence suggests that drug court participation is associated with reductions in recidivism and illicit substance use; ${ }^{11}$ however, these approaches still raise questions about why courts are tasked with managing health-related issues for people arrested solely for PSUP, which may be a manifestation of a SUD. In addition, considering, evaluating, and addressing structural racism needs to be part of these types of reforms; embedding health-oriented drug treatment courts in criminal justice systems may not eliminate racial disparities in outcomes.

Decriminalizing use or possession of small amounts of controlled substances, as more than 20 states have done with cannabis, could prevent substantial criminal justice involvement; yet these reforms could also lead to conflicts between federal and state policies, and the FBI still reported over 545,000 cannabis-related arrests in 2019, of which $92 \%$ were for possession. By comparison, Portugal decriminalized PSUP of all illicit drugs in 2001, shifting toward a health-oriented approach. Advocates for US drug policy reform often point to decreased HIV transmission and low overdose rates as evidence of this reform's success; still, there has been debate over the degree to which decriminalization influenced these findings and other substancerelated outcomes. ${ }^{12}$

Oregon's experience can offer lessons for the rest of the country. This new approach should be studied to understand its effects on substance-associated morbidity and mortality, public safety, law enforcement-related disparities, and other quality of life indicators. Many questions remain, including whether these efforts might extend to expungement of drug-related criminal records. For now, Oregon's voters have sent a strong message - one that supports the health, dignity, and equitable treatment, rather than the criminalization, of people who possess and consume substances for personal use. 
Corresponding Author: Robert A. Kleinman, MD; Massachusetts General Hospital, 55 Fruit St., Boston, MA 02112, USA (e-mail: rakleinman@mgh.harvard.edu).

\section{Declarations:}

Conflict of Interest: The authors do not have any conflicts of interest to disclose.

\section{REFERENCES}

1. Carson E. Prisoners in 2019. U.S. Department of Justice, Bureau of Justice Statistics; 2020. Accessed 17 Dec 2020. Available from: https:// www.bjs.gov/content/pub/pdf/p19.pdf

2. Bronson J, Zimmer S, Berzofsky M. Drug Use, Dependence, and Abuse Among State Prisoners and Jail Inmates, 2007-2009. U.S. Department of Justice, Bureau of Justice Statistics; 2017. Available from https://www. bjs.gov/content/pub/pdf/dudaspji0709.pdf. Accessed 7 Jul 2020.

3. Vagins DJ, McCurdy J. Cracks in the System: 20 Years of the Unjust Federal Crack Cocaine Law. New York, NY: American Civil Liberties Union. Accessed 16 Dec 2020. Available from: https://www.aclu.org/ other/cracks-system-20-years-unjust-federal-crack-cocaine-law

4. Beckett K, Nyrop K, Pfingst L. Race, drugs, and policing: understanding disparities in drug delivery arrests. Criminology 2006;44(1):105-37.
5. Bureau of Justice Statistics. Arrest Data Analysis Tool. Available from: https://www.bjs.gov/index.cfm?ty=datool\&surl=/arrests/index.cfm\#. Accessed 2 Feb 2021.

6. Center for Behavioral Health Statistics and Quality, Substance Abuse and Mental Health Services Administration. 2018 National Survey on Drug Use and Health: Detailed Tables. Rockville, Maryland: 2020.

7. Gelb A, Stevenson P, Fifield A, et al. More Imprisonment Does Not Reduce State Drug Problems. Available from: http://pew.org/2tszeZl. Accessed 9 Jul 2020.

8. Alper M, Durose MR, Markman J. 2018 Update on Prisoner Recidivism: A 9-year Follow-up Period (2005-2014). U.S. Department of Justice, Bureau of Justice Statistics; 2018. Available from: https://www.bjs.gov/ content/pub/pdf/18upr9yfup0514.pdf. Accessed 9 Jul 2020.

9. Ranapurwala SI, Shanahan ME, Alexandridis AA, et al. Opioid Overdose Mortality Among Former North Carolina Inmates: 2000-2015. Am J Public Health 2018;108(9):1207-13.

10. Patterson EJ. The Dose-Response of Time Served in Prison on Mortality: New York State, 1989-2003. Am J Public Health 2013;103(3):523-8.

11. Brown RT. Systematic review of the impact of adult drug treatment courts. Transl Res 2010;155(6):263-74.

12. Laqueur $\mathbf{H}$. Uses and Abuses of Drug Decriminalization in Portugal. Law soc inq 2015;40(03):746-81.

Publisher's Note: Springer Nature remains neutral with regard to jurisdictional claims in published maps and institutional affiliations. 